\title{
Evaluation of National Innovation System in Developing Economies: A Namibian Perspective
}

\author{
Asa Romeo $\mathrm{Asa}^{1}$, Navneel Shalendra Prasad ${ }^{2}$, Maw Maw Htay ${ }^{3}$ \\ ${ }^{1,2}$ School of Management, ${ }^{3}$ School of Mechanical and Electronic Engineering \\ Wuhan University of Technology, Wuhan, 430070, P.R. China
}

\begin{abstract}
In today's globalized economy, through which countries are vying for economic strength, prosperity, and the capability to compete in the global economy all reckons on valuing innovation, harnessing its potential and laying it to work for the benefit of all the country's citizens. This paper aims at investigating the Namibian national innovation system. We explore the concept of national innovation system and discuss the significance in fostering innovation for the country's economy. Development stages of Namibia in terms of innovation are also examined, given that national economic performance is closely related to the country's effectiveness to create an environment that is favorable for generating innovations. The evolution and analyses of Namibian NIS by determining innovation actors, defining the linkages between them through a "3Ms triangle" and evaluating their contribution to the national innovativeness and competitiveness are covered. As a final point, we categorize the Namibian national innovation system according to its development stage and draw some strategic implications in order to strengthen the Namibian national innovation system.
\end{abstract}

Keywords: National Innovation System, Real GDP, National Development Plan

\section{Introduction}

The ability to innovate is a universally adopted perspective among researchers as a major factor of competitiveness, hence seen as a driver of the long-term economic prosperity. The government's crucial role is to create an environment that promote and enhance companies' ability to innovate for the benefit of the nation. Developing innovation on an organizational, industrial, regional and national level is considered essential for job creation, growth and sustainable wealth generation [9]. Successful economic and industrial development is intimately linked to a nation's capacity to acquire, absorb and disseminate modern technologies, especially in labor markets, industrial relations and inter-firm relationship [3].

Foreign direct investment is an essential tool for developing nations in acquiring technologies which aim at improving the economic conditions and prosperity of a nation that depends on the industries' and organizations' capacity to innovate continuously. Additionally, this capability is considered a primary source of organization's sustained competitive advantage [8]. Taking into consideration that overwhelming majority of innovations come from organizations, hence comprehending the innovativeness of industries and organizations is therefore of essential importance to any nations' government, particularly for the reason that the increased international competition puts additional pressure on nations' organizations to be competitive. Competitiveness doesn't depend solely on the existence of production factors and skilled labor force; however, a well-planned and accurately designed policy of stimulating innovations can serve as an effective tool in attaining competitiveness.

The government is the one that establishes satisfactory framework conditions and encourages innovation in firms through its policy measures. Namibia is vastly endowed with natural resources such as diamond and uranium; however the fact the countries which mainly export minerals and other raw materials are even getting poorer than countries that import the minerals and raw materials and transform them into sophisticated goods are the ones increasing the size of their wealth. Attaining conditions which fuels the innovation process is not an easy task. However, generating innovations requires development of policies that support innovation appropriately. This implies understanding the critical aspects of the innovation through investing large sums in research, science and technology.

\section{Concept of National Innovation System}

Innovation may be considered as one of the main drivers for economic competitiveness, growth and wealth creation. Therefore, innovation policy has become an important part of economic policy in catching up nations. It is essential for governments to develop policies that create and strengthen innovation performance and outcomes. The design of suitable framework conditions for innovation reflected by the maturity level of national innovation system (NIS) has been given high priority worldwide. Although there is no common definition of an NIS, the following definition best suits the notion of this research; The set of distinct institutions which jointly and individually contribute to the development and diffusion of new technologies and which provides the framework within which governments form and implement policies to influence the innovation process. As such it is a system 
of interconnected institutions to create, store and transfer the knowledge, skills and artifacts which define new technologies [5].

The concept of an NIS relies on the premise that a good understanding of innovation actors and their relationships is crucial to foster technology performance. Innovation and technological progress are indeed outcomes of a complex set of relationships among NIS actors producing, distributing and implementing various kinds of knowledge. The innovative performance of a country broadly depends on the actors in cooperation within a global knowledge creation system and on the extent to which they utilize technologies; the actors are mainly private enterprises, universities and public research institutes.

Firstly, the impact of innovation is important across different countries and institutional contexts. But the nature and role of innovation differ at different levels of economic development. In low-middle income developing countries, entrepreneurs provide innovations that are important for firms and growth of country as a whole, even though are incremental in nature. Innovation in developing countries revolve around the process by which firms master and implement the design and production of goods and services that are new to them which are acquired from industrialized nations. Many small improvements in product design and quality, changes in the way production is organized, creativity in marketing and modifications in production processes and techniques reduce costs, also increase efficiency and flexibility to respond to changes in competitive conditions which result in enhanced productivity and employment growth.

Innovation plays an important role in catching-up and growth of developing economies in a globalized economy; this is due to the varied innovations realized by local entrepreneurs in developing countries. Considerately, it also depends on the activities of entrepreneurs in advanced economies, where innovations are generated that subsequently spread to developing countries, and applied in their particular local contexts.

\section{Economic Performance of Namibia}

Namibia is an efficiency driven economy according to the Global Competitiveness Report 2012- 2013, while ranked number 73 in Global Innovation Index rankings 2012, with score of 34.1, literally this means that Namibia is the $3^{\text {rd }}$ innovative country in Sub-Saharan Africa after Mauritius and South Africa respectively. We can justify that Namibia as a catching up economy has efficient production processes that increase the quality of the products including efficient commodity markets, financial markets, and labor markets. The most competitive factors recognized in Namibia are education and training. Figure 1 illustrates a comparative outlook of Namibia's real GDP benchmarking it with Southern Africa counterpart and Africa at large.

Figure 1: Real GDP growth

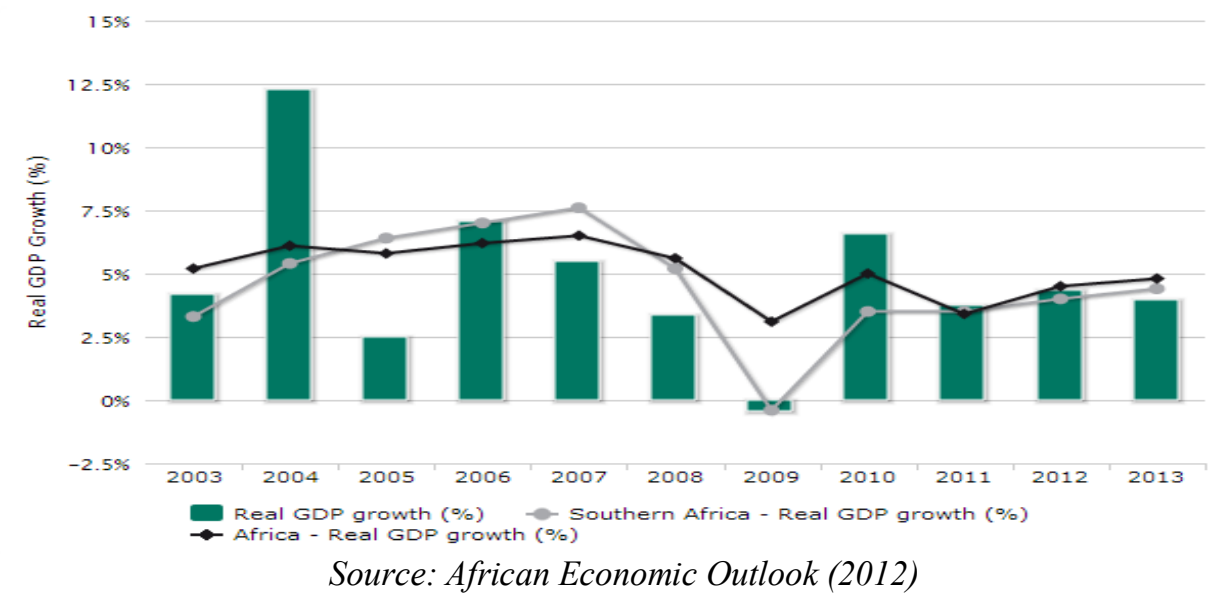

Namibian economy is intemperately dependent on the extraction and processing of minerals for export, heavily on diamonds and Uranium. The above graph depicts the Namibian economy is volatile from high growths and drastic falls which is evident from 2009 to 2011 showing a slowed down growth in 2011 with the GDP growth rate of $3.8 \%$, down from $6.6 \%$ in 2010 , reflecting modest performances in mining and agricultural activities. According to the African Economic Outlook (2012), Prospects for the medium-term remain favorable with GDP growth projected to continue on its path of recovery to an average of 4.2 percent for the years 2012 and 2013 , driven by construction, livestock and crop farming, manufacturing and mining.

The fiscal situation in Namibia has deteriorated substantially, reflecting the global economic crisis and expansionary policies to support economic growth, after years of fiscal surpluses arising from prudent macroeconomic policies. The budget for 2011/12 provided the continuation of the expansionary fiscal policy for the fourth successive year as the Government commences the implementation of the three-year Targeted 
Intervention Programme for Employment and Economic Growth (TIPEEG), totaling 14.7 billion Namibian dollars (NAD), aimed at creating and retaining 104000 jobs. As a result, the fiscal deficit is expected to widen, averaging nearly 6.5\% of GDP between 2011/12 and 2012/13 (African Economic Outlook, 2012). The deficit is financed by domestic borrowing and foreign debt. Namibia's debt levels have risen in recent years, but remain sustainable and below the $30 \%$ threshold, despite the expansionary fiscal policy [1].

Risks to Namibia's positive medium-term outlook include a severe slowdown in the global economy emanating from the sovereign debt crisis Euro zone and the structural reductions in the Southern Africa Customs Union (SACU). It is also clouded by the country's massive challenges of poverty, high unemployment and inequality in income distribution.

\section{Evolution of Namibian National Innovation System}

Namibia's Vision 2030 adopted by Cabinet in June 2004, which aims to transform Namibia into a prosperous and industrialized country, serves as the foundation and backbone of the Namibian National Innovation System (NIS). Industrialization of a country can only be attained through high-tech and innovation in a knowledge based society. In the context of Namibia is evident that policies aimed at national innovation are rooted in 5 year term plans known as the National Development Plans (NDPs), which are the main instruments for implementing the policies and programs to achieve Vision 2030.

Vision 2030 establishes a long-term planning system for Namibia with the aim of fostering a sense of direction, discovery and destiny among the Namibian nation [6]. The Namibian governments show its interest in transforming Namibia into an industrialized nation until 2030 with the third National Development Plan (NDP3): NDP3 covers the period 2008-2012 to create Namibia as a "knowledge-based and technology driven nation". The destiny of Vision 2030 through National Development Plans offers a systematic process for developing and implementing consistent long-term development strategies, based on all stakeholders actively participating at each stage of the process, and linking Vision 2030 to existing five-year "National Development Plans" (NDPs) which are the implementation tools for the developments of Namibia.

A comprehensive view at the strategic objectives such as competent and highly productive human resources, an industrialized country, a knowledge based, and highly competitive nation; and the pillars such as the human resource development and technological innovation towards Namibia's Vision 2030, clearly indicates a government effort towards the notion of national innovation in its plans and policies.

\section{Actors of National Innovation System in Namibia}

NIS in Namibia comprises of three levels namely macro, meso and micro, also referred to as the $3 \mathrm{Ms}$ in this research paper. Figure 2 portrays the scenario of the Namibian innovation system by clearly showing levels, actors and their functions within an NIS. The $3 \mathrm{Ms}$ Triangle can also be matched and applied to the strategic (policy), tactical (procedure) and operational (execution) levels in business organizational hierarchy.

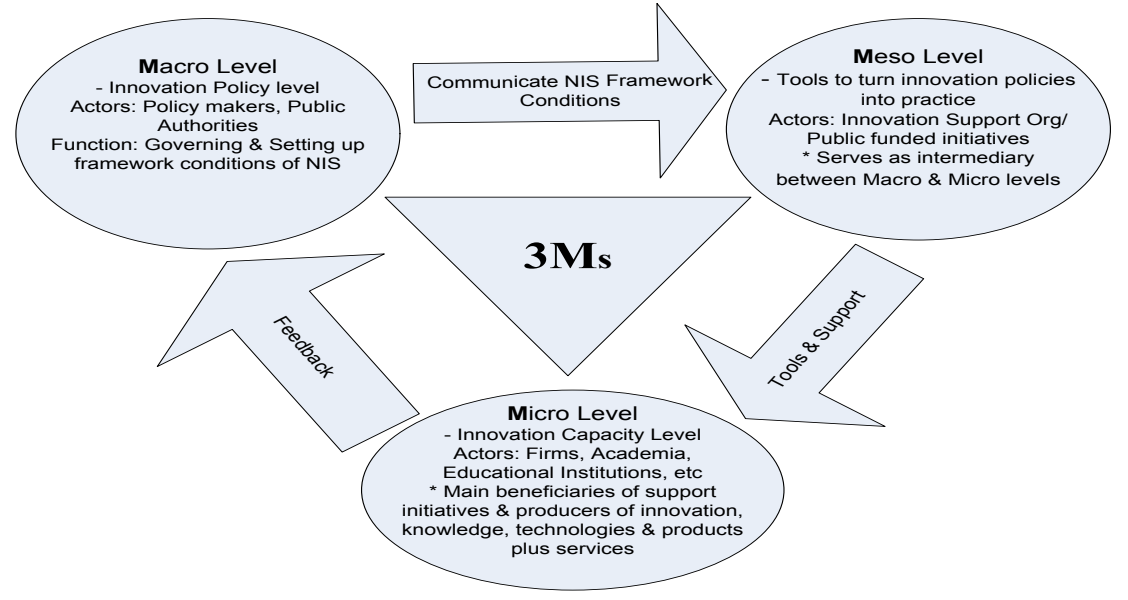

Figure 2: The 3Ms Triangle of NIS

\subsection{Macro Level}

The policy makers and public authorities are the main actors at macro level in dictating innovation policy. Their main function is to culminate in the motivation to promote the generation of the Namibian innovation system through regulating and setting up framework conditions of a national innovation system. Namibia's innovation is hardly developed at all with regard to innovation policy in all respects on global competitive level. Investment in national research and innovation is largely dependent on decisions made by politicians at the policy level. Most of these political decisions turn out as mere documented files rather than practical developments in 
seeing that the framework conditions are implemented and follow-up at different development stages and stakeholders such as government ministries, private sector and the educational and research institutions.

Theoretically, the framework conditions for system of innovation in Namibia are prudent and potential, however there lack pragmatic approach in coordinating all stakeholders to incorporate the innovation policies in place.

\subsection{Meso Level}

At meso level there are two dimensions that serve as tools in turning innovation policies into practice namely the institutional innovation support level and programmatic innovation support level. The main actors are the institutional innovation support organizations and public funded initiatives respectively that serve as intermediaries between the policy level and the micro level actors such as firms and educational institutions. The actors at meso level are pivotal in turning political decisions based on innovation into practice, generally are technology transfer centers, innovation service providers, clusters and financial support agencies which require significant public investments.

In Namibia most of these organization bodies are initiatives owned by the government, such as The Directorate of Industrial Development inside the Ministry for Trade and Industry (MTI) is responsible for evaluating and appraising industrial projects by rendering support and advice to potential developers and investors. Also the Namibia Business Innovation Centre (NBIC) carries out a variety of measures to develop a culture of entrepreneurship, invention, innovation and skills. NBIC promotes the innovation environment through workshops, technology and product competitions, business plan competitions and trainings. These institutions in Namibia remain vital for improving and advocating the innovation capabilities of firms to be competitive and grow into bigger companies that can curb Namibia's unemployment pandemic.

\subsection{Micro Level}

At this level the actors are the main producers of innovation, technologies, knowledge and goods plus services. It is an innovation capacity level within an NIS carried out by entrepreneurs, SMEs, universities, R\&D institutions, innovators and financial organizations. Feedback is necessary to both the macro and micro levels to monitor the progress on the innovation investments and take corrective measures where required. The linkage on the feedback part is counteracting as there are no measures to track the progress of the innovations not only at micro level but at all levels of NIS. The status quo of innovation in Namibia is under developed; Namibia is rated low in the area of innovation.

Though Namibia is the third innovative rated country in Sub Saharan Africa according to the Global Innovation Index 2012, still need large investments in research and science to improve its technological and innovation capacity, Namibia been rated the third in innovation its region with the evident low statistics of innovation, in fact this means the developing African countries are abject in the context of innovation. To catch up with the industrialized nations the innovation agenda must be highly advocated in the national plans and acquire innovation and technological know-how from advanced countries in order to bridge the gap.

\section{Strategic Implications}

The significances outlined below are aimed to strengthen the Namibian national innovation system.

Investing in innovation, knowledge creation and enabling its diffusion is the pivotal to creating high-wage employment and enhancing productivity, therefore public investment in education, research and technology should be the first priority.

We live in a dynamic changing world; governments must ensure that the policy framework for NIS keeps pace with changes in the global economy and changes in the innovation process. The world faces the reality of agile technology changes, that policies become outdated, which apt the policy makers to keep on track and understand that, innovation is the way forward to improve the quality of life and address major social and global problems that Namibia face.

The importance of internet in innovation should not be underrated, the government must invest in internet, the Namibian citizens must have affordable and access to use of internet. The internet provides opportunities for an organization to enhance its business in a cost effective and practical manner [12]. Internet is significant in driving the nation into a knowledge based economy and prompt communications with current affairs, communication between levels of NIS is also enhanced through use of internet. Moreover, the internet boosts innovation and knowledge diffusion through increased information flow and makes it easier to access local and global markets.

\section{Conclusions}

Our research provides an insight into the development of the National Systems of Innovation in an efficiency driven country and additionally it will be valuable for policy makers and other actors trying to create 
and develop effective national systems of innovation. In developing economies like Namibia, innovation is the way forward to catching up with the industrialized economies. It is fundamental to strengthen linkages between all the actors within the NIS and take strategic approaches to fostering innovation to achieve the core objectives of public policy. After evaluating the Namibian national innovation system based on its prudent macroeconomic policies, we can conclude that Namibia is in the right direction; however, Namibia still needs to enhance its pragmatic approach to innovation.

[1] African Economic Outlook, OECD. 2012

\section{References}

[2] Asa, R. Adoption of Cell-Phone Banking in Namibia: Case Study of First National Bank. CAMAN. 2012

[3] Feinson, S. Knowledge Flows, Innovation, and Learning in Developing Countries. CSPO Research. 2003

[4] Fostering Innovation: The Policy Challenge. OECD Publishing. 2010

[5] Metcalfe, J. Technology Systems and Technology Policy in an Evolutionary Framework. Cambridge Journal of Economics. 1995

[6] Namibia Vision 2030. (2004). Background of Vision 2030. Retrieved from: http://www.npc.gov.na/vision/pdfs/Chapter 1.pdf. Retrieved on July 12, 2012

[7] Peter, H. Gerd, M. Lysann, M. Indicator-Based Analysis of National Innovation System. Institute for Innovation and Technology, Berlin. 2010

[8] Porter, M. The Competitive Advantage of Nations. Harvard Business Review. 1990

[9] Roos, G. NIS: Finland, Sweden and Australia Compared. Australia Business Foundation. 2005

[10] Schwab, Klaus (Ed.) (2012). The Global Competitiveness Report 2012-2013. Geneva: World Economic Forum.

[11] Soumitra, D. The Global Innovation Index 2012. INSEAD and WIPO. 2012

[12] The Innovator's Advantage. Accenture. 2004 